\title{
electrode-respiring biofilms
}

The Gene and Linda Voiland School of Chemical Engineering and Bioengineering,

Washington State University, Pullman, Washington

17 *Corresponding author:

18 E-mail: beyenal@wsu.edu; Telephone: +1-509-335-6607; Fax: +1-509-335-4806

19

20

21

22 
Abstract

25 The goal of this work was to develop a microbiosensor to measure acetate concentration profiles inside biofilms in situ. The working principle of the microbiosensor was based on the correlation between the acetate concentration and the current generated during acetate oxidation by Geobacter sulfurreducens. The microbiosensor consisted of a 30- $\mu \mathrm{m}$ carbon microelectrode with an open tip as a working electrode, with G. sulfurreducens biofilm on the tip and a pseudo $\mathrm{Ag} / \mathrm{AgCl}$ reference electrode, all enclosed in a glass outer case with a $30-\mu \mathrm{m}$ tip diameter. The microbiosensor showed a linear response in the $0-1.6 \mathrm{mM}$ acetate concentration range with a 79 $\pm 8 \mu \mathrm{M}$ limit of detection $(\mathrm{S} / \mathrm{N}=2)$. We quantified the stirring effect and found it negligible. However, the interfering effect of alternative electron donors (lactate, formate, pyruvate, or hydrogen) was found to be significant. The usefulness of the acetate microbiosensor was demonstrated by measuring acetate concentration depth profiles within a G. sulfurreducens biofilm. The acetate concentration remained at bulk values throughout the biofilm when no current was passed, but it decreased from the bulk values to below the detection limit within $200 \mu \mathrm{m}$ when current was allowed to pass. The zero acetate concentration at the bottom of the biofilm showed that the biofilm was acetate-limited.

Keywords: Microbiosensor, acetate, biofilm, Geobacter, electron transfer, microelectrode. 


\section{Introduction}

Needle-type microelectrodes are among the most used and valuable tools in biofilm research. With tip dimensions on the order of tens of microns, they can be used to monitor the microscale gradients in biofilms without damaging biofilm structure. Direct measurement of these gradients provides critical information on the local physicochemical environment in which the cells within biofilms respire and therefore yields important mechanistic information. Typically, the physicochemical parameters measured using microelectrodes include $\mathrm{pH}$, dissolved oxygen concentration, and redox potential (Lee et al. 2007; Lewandowski et al. 1989; VanHoudt et al. 1992). This list has expanded significantly to include $\mathrm{H}_{2} \mathrm{~S}, \mathrm{CO}_{2}, \mathrm{NO}_{2}^{-}$, and $\mathrm{H}_{2} \mathrm{O}_{2}$ microelectrode measurements (Beyenal et al. 2004; De Beer et al. 1997b; Jeroschewski et al. 1996; Liu et al. 1998). In addition, microbiosensors have been constructed with immobilized microorganisms, e.g. glucose, methane, nitrate, nitrous oxide, and galactose microbiosensors (Cronenberg and van den Heuvel 1991; Damgaard and Revsbech 1997; Larsen et al. 1996; Lewandowski and Beyenal 2003; McLamore et al. 2011; Peteu et al. 1996). Because of challenges in their construction and operation, the number of available microbiosensors is limited. New microbiosensors are needed to quantify electron donor concentrations in biofilms (Renslow et al. 2013).

Acetate is one of the electron donors used for biofilms growing and transferring electrons to solid electrodes in microbial fuel cells or in bioelectrochemical systems (Hamelers et al. 2010; Logan 2009). This type of biofilms is called electrochemically active biofilms, and they are able to transfer electrons out of the cell to electrodes via extracellular electron transfer (Du et al. 2007; Logan et al. 2006; Lovley 2006). Electrochemically active biofilms are able to transfer electrons out of the cell and to the electrode surface directly using their outer membrane proteins or using electron transfer mediators (Logan and Rabaey 2012). Many bacterial species are capable of extracellular electron transfer. However, only a few are able to respire at extreme rates because of their conductive nature (Reguera et al. 2005). In particular, Geobacter sulfurreducens biofilms are able to respire on acetate using a solid electrode as the terminal electron acceptor (Bond and Lovley 2003). G. sulfurreducens biofilms form thick, stable biofilms on electrodes that tend to remain on the electrode surfaces even in the absence of acetate. These properties of G. sulfurreducens biofilms make it an excellent candidate for converting acetate to electricity on electrodes. It is not clear whether current generation by G. sulfurreducens biofilms is limited by acetate diffusion in biofilms. To address this question, Renslow et al. recently used an electrochemical nuclear magnetic resonance (EC-NMR) microimaging system to measure acetate concentration depth profiles in situ in biofilms (Renslow et al. 2013). The acetate concentration measurement limit was $\sim 1 \mathrm{mM}$, and measurements were averaged over a $20 \mu \mathrm{m} \times 4 \mathrm{~mm} \times 2 \mathrm{~mm}$ volume. It was found that a bulk acetate concentration above $2.3 \mathrm{mM}$ does not limit the current from G. sulfurreducens (Tront et al. 2008). Therefore, a technology which can measure acetate concentration sensitively below $\mathrm{mM}$ concentrations is needed to understand acetate limitations in G. sulfurreducens biofilms. This is especially critical when a biofilm is thicker than hundreds of microns. Thus, a microelectrode capable of measuring acetate directly within biofilms in the micromolar range would prove useful in linking acetate concentration to local metabolisms in biofilms and identifying whether acetate completely limits biofilm growth. Since G. sulfurreducens biofilms can use electrodes as their sole electron acceptor under anaerobic conditions, a microelectrode in a needle-type microbiosensor can be used to detect acetate concentrations amperometrically. To the best of our knowledge, there is currently no microbiosensor which can measure $\mu \mathrm{M}$-level acetate concentrations in situ within biofilms. 
The goal of this work was to develop a microbiosensor based on G. sulfurreducens to measure local acetate concentrations in situ within biofilms. The developed acetate microbiosensor was based on the extracellular electrons generated during acetate consumption by G. sulfurreducens biofilm growing on the tip of a carbon microelectrode (this is referred to as a microelectrode-biofilm). Though the microelectrode-biofilm oxidizes acetate efficiently over other possible metabolites, we also tested the microbiosensor response to various alternative electron donors. Once we had developed and calibrated the microbiosensor, we tested it to measure acetate concentration depth profiles inside a G. sulfurreducens biofilm grown on a large glassy carbon electrode (macro-biofilm) when no current was passed and when current was passed.

\section{Materials and Methods}

\subsection{Acetate microbiosensor construction}

The construction of the acetate microbiosensor is detailed in the Supplementary Information (SI). Briefly, the microbiosensor was constructed by placing a carbon microelectrode and a bare $\mathrm{Ag} / \mathrm{AgCl}$ reference electrode into a glass outer case as shown in Figure 1a. A photograph of the assembled microbiosensor is also shown in the SI. The carbon wire used to construct microbiosensors was a 30- $\mu$ m-diameter electrochemically activated carbon fiber (World Precision Instruments, Sarasota, FL, USA, catalog \#C3005). The construction of the glass capillary — sealing the carbon wire, covering the carbon wire with glass, making the glass outer case out of a pulled Pasteur pipette, and making the silver/silver chloride reference electrodehas been detailed in the SI and previously (Nguyen et al. 2012). Following the construction of the microbiosensor parts, the microelectrode tip (diameter: $30 \mu \mathrm{m}$ ) and the glass outer case tip (diameter: $30 \mu \mathrm{m}$ ) were first assembled under $40 \times$ microscope magnification using micromanipulators. The carbon microelectrode was inserted into the outer case, with its tip positioned $\sim 200 \mu \mathrm{m}$ behind the outer case tip (Figure 1a). We should note that the carbon wire was completely covered by glass except for the tip, where the biofilm and carbon wire were electronically connected. The microelectrode was then glued to the outer case using five-minute epoxy. At least one hour was allotted to ensure that the drying process was completed. Finally, a $\mathrm{Ag} / \mathrm{AgCl}$ reference electrode made of silver wire (Sigma-Aldrich, St. Louis, MO, USA, 0.25-mm diameter, $\geq 99.99 \%$ pure, catalog \#327034) was inserted and glued in place using five-minute epoxy. The G. sulfurreducens microelectrode-biofilm shown in Figure 1 was grown later on a carbon microelectrode after the microbiosensor parts were assembled.

\subsection{Sensing mechanisms of the proposed acetate microbiosensor}

The transducer is the microelectrode-biofilm inside the outer case (Figure 1). The medium containing acetate diffuses through the open tip with a $\sim 30-\mu \mathrm{m}$ diameter. Then, acetate is oxidized by a pre-grown G. sulfurreducens biofilm on the carbon-wire microelectrode (Figure 1b) according to the following reaction (He and Angenent 2006):

$$
\mathrm{CH}_{3} \mathrm{COO}^{-}+4 \mathrm{H}_{2} \mathrm{O} \stackrel{\text { G. sulfurreducens biofilm }}{\longrightarrow} 2 \mathrm{HCO}_{3}^{-}+9 \mathrm{H}^{+}+8 \mathrm{e}^{-} \quad \mathrm{E}^{\circ}=-483 \mathrm{mV}_{\mathrm{Ag} / \mathrm{AgCl}}
$$


The electrons generated from this reaction are passed to the counter electrode (CE), which also acts as a reference electrode (RE). The reaction on the CE/RE is given below (Lewandowski and Beyenal 2014).

$$
\mathrm{AgCl}+\mathrm{e}^{-} \leftrightarrow \mathrm{Ag}_{(\mathrm{s})}+\mathrm{Cl}^{-} \quad \mathrm{E}^{\mathrm{O}^{\prime}}=0 \mathrm{mV} \mathrm{Ag} / \mathrm{AgCl}
$$

Equation (2)

We should note that since the current passed between the working electrode and RE is on the order of nanoamperes, we successfully used a pseudo Ag/AgCl RE. At this level of current, the $\mathrm{RE}$ was not damaged by the current. We also compared our measurements using a threeelectrode system with a graphite counter electrode and the response was identical to that of a two-electrode system (results not shown). Therefore, we used a two-electrode microbiosensor in which the RE also served as the CE. As detailed later in this paper, the current generated from acetate oxidation (Equation 1) is correlated with the acetate concentration.

\subsection{Bioelectrochemical reactor}

G. sulfurreducens biofilms were grown on the carbon microelectrode tips within a temperature-controlled electrochemical cell (Gamry Instruments \#990-00249) nearly identical to the setup used in (Babauta and Beyenal 2014b) but with the following modifications. The cell was operated in batch mode with $150 \mathrm{~mL}$ of growth medium. Microelectrodes replaced the macroelectrodes. The counter electrode was a graphite rod (Sigma-Aldrich \#496545), and the reference electrode was a custom-made $\mathrm{Ag} / \mathrm{AgCl}$ electrode filled with saturated $\mathrm{KCl}$. A mixture of $\mathrm{N}_{2} / \mathrm{CO}_{2}(80 \% / 20 \%)$ gas was sparged using a $0.2-\mu \mathrm{m}$ filter to maintain anaerobic conditions. The complete electrochemical cell setup except for the microelectrodes and the reference electrode was autoclaved for $20 \mathrm{~min}$ at $121^{\circ} \mathrm{C}$. The growth medium was autoclaved separately in a 2-L autoclavable glass bottle (Corning \#1395-2L) for $20 \mathrm{~min}$ at $121{ }^{\circ} \mathrm{C}$. Once the growth medium cooled, $150 \mathrm{~mL}$ of it was aseptically added to the electrochemical cell. The reference electrode and the microelectrodes were sterilized, first using $70 \% \mathrm{v} / \mathrm{v}$ ethanol, then drying under UV exposure for 45 min prior to insertion into the electrochemical cell. Since the tip of the outer case was open, the tip was partially filled with sterilized growth medium, up to $\sim \mathrm{mm}$ from the tip after insertion. The temperature was controlled using a Fisher Scientific Model 910 water bath at $30^{\circ} \mathrm{C}$ circulated using the built-in glass jacket. 
a)

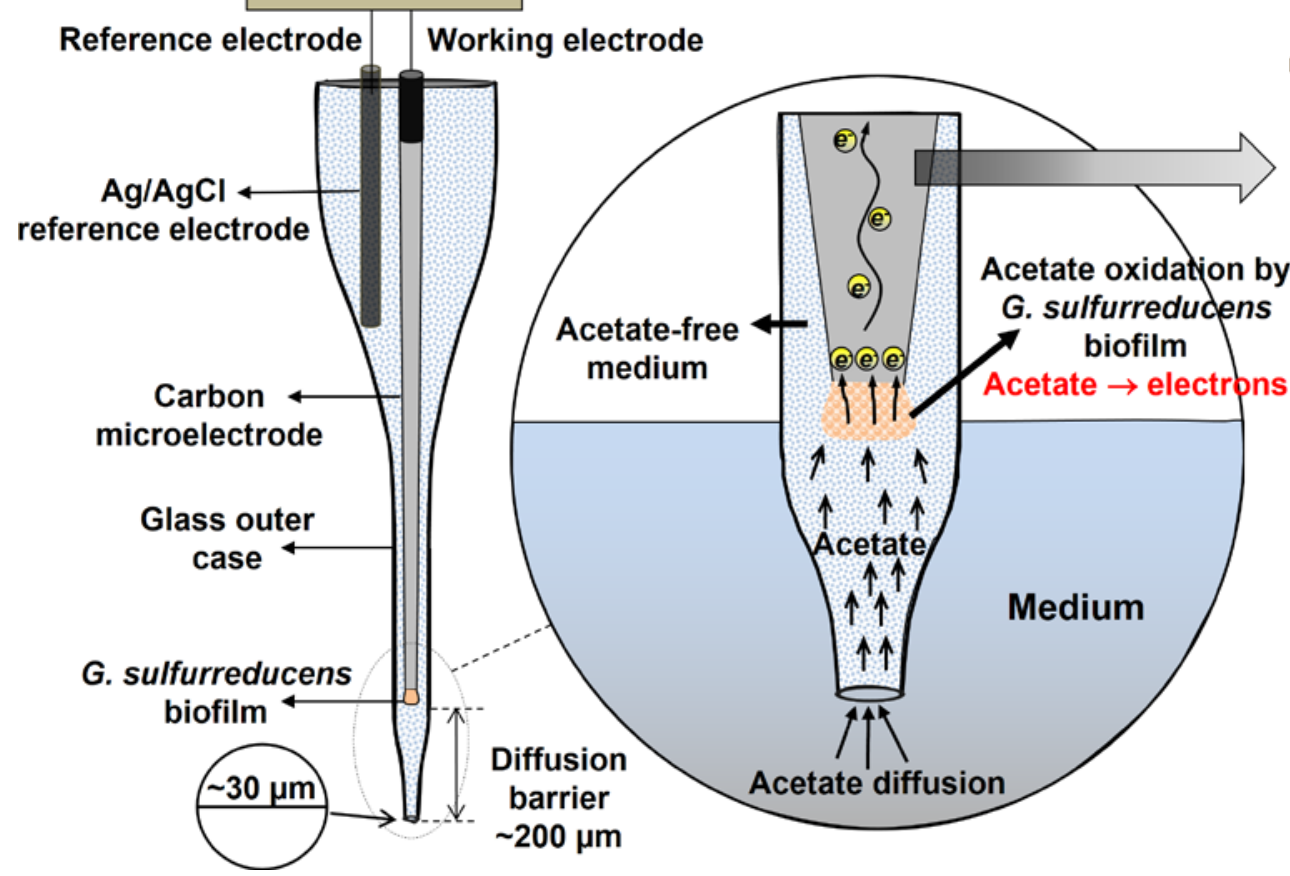

b)

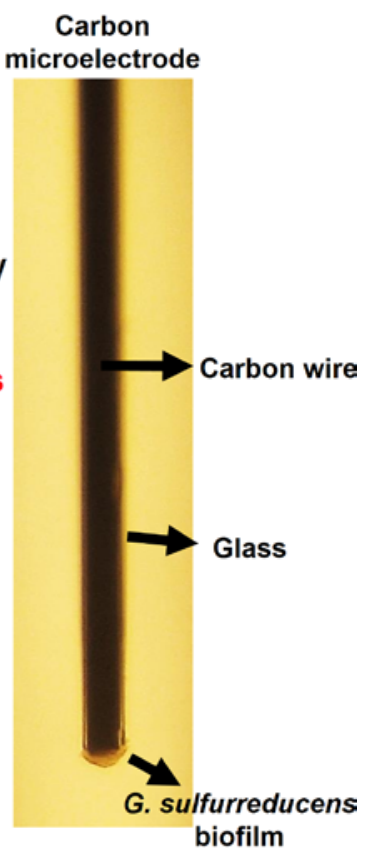

Figure 1. a) The acetate microbiosensor consists of a carbon microelectrode with a tip diameter of $30 \mu \mathrm{m}$, a Ag/AgCl reference electrode, and an outer case. b) Photo of the carbon microelectrode with $G$. sulfurreducens microelectrode-biofilm grown on the tip. Figure not drawn to scale.

\subsection{Growth medium}

The growth medium used to grow G. sulfurreducens strain PCA (ATCC 51573) biofilms was prepared according to the following recipe (Babauta et al. 2012): potassium chloride, $0.38 \mathrm{~g} / \mathrm{L}$; ammonium chloride, $0.2 \mathrm{~g} / \mathrm{L}$; sodium phosphate monobasic, $0.069 \mathrm{~g} / \mathrm{L}$; calcium chloride, $0.04 \mathrm{~g} / \mathrm{L}$; magnesium sulfate heptahydrate, $0.2 \mathrm{~g} / \mathrm{L}$; sodium bicarbonate, $2 \mathrm{~g} / \mathrm{L}$; Wolfe's vitamin solution, $10 \mathrm{~mL} / \mathrm{L}$; modified Wolfe's mineral solution, $10 \mathrm{~mL} / \mathrm{L}$. Acetate was provided (20 mM). There was no fumarate or other soluble electron acceptor in the growth medium.

\subsection{Growing microelectrode-biofilms}

Prior to inoculation, the electrochemical cell was sparged with a gas mixture of $\mathrm{N}_{2} / \mathrm{CO}_{2}$ $(80 \% / 20 \%)$ for at least $24 \mathrm{~h}$ to remove oxygen from the system. Carbon microelectrodes were polarized continuously at $+300 \mathrm{mV}$ Ag/AgCl using a Gamry Interface 1000 (Gamry Instruments, Warminster, PA) to measure a background current. Fifteen $\mathrm{mL}$ of $\mathrm{G}$. sulfurreducens inoculum was then added, which was prepared according to a previously published procedure (Babauta et al. 2012). Within 24 h, a current response was observed. Figure 2a shows the microelectrodebiofilm current response for $\sim 120$ hours of growth after inoculation. Based upon prior work (Babauta and Beyenal 2014a), the current was expected to be $\sim 40 \mathrm{nA}$, although longer growth times could result in current up to $60 \mathrm{nA}$. Cyclic voltammograms (CVs) were taken for each microelectrode at $\mathrm{t}=24 \mathrm{~h}$ and $\mathrm{t}=160 \mathrm{~h}$. A representative microelectrode-biofilm $\mathrm{CV}$ is shown in Figure $2 \mathrm{~b}$. At $\mathrm{t}=24 \mathrm{~h}$ before the inoculation, the current response was flat, while a CV taken after the growth (at $\mathrm{t}=160 \mathrm{~h}$ ) is characteristic of $\mathrm{G}$. sulfurreducens biofilm. The limiting current was 
observed after $-200 \mathrm{mV}_{\mathrm{Ag} / \mathrm{AgCl}}$ (Fricke et al. 2008). A photo of the microelectrode-biofilm is 203 shown in Figure 1d.
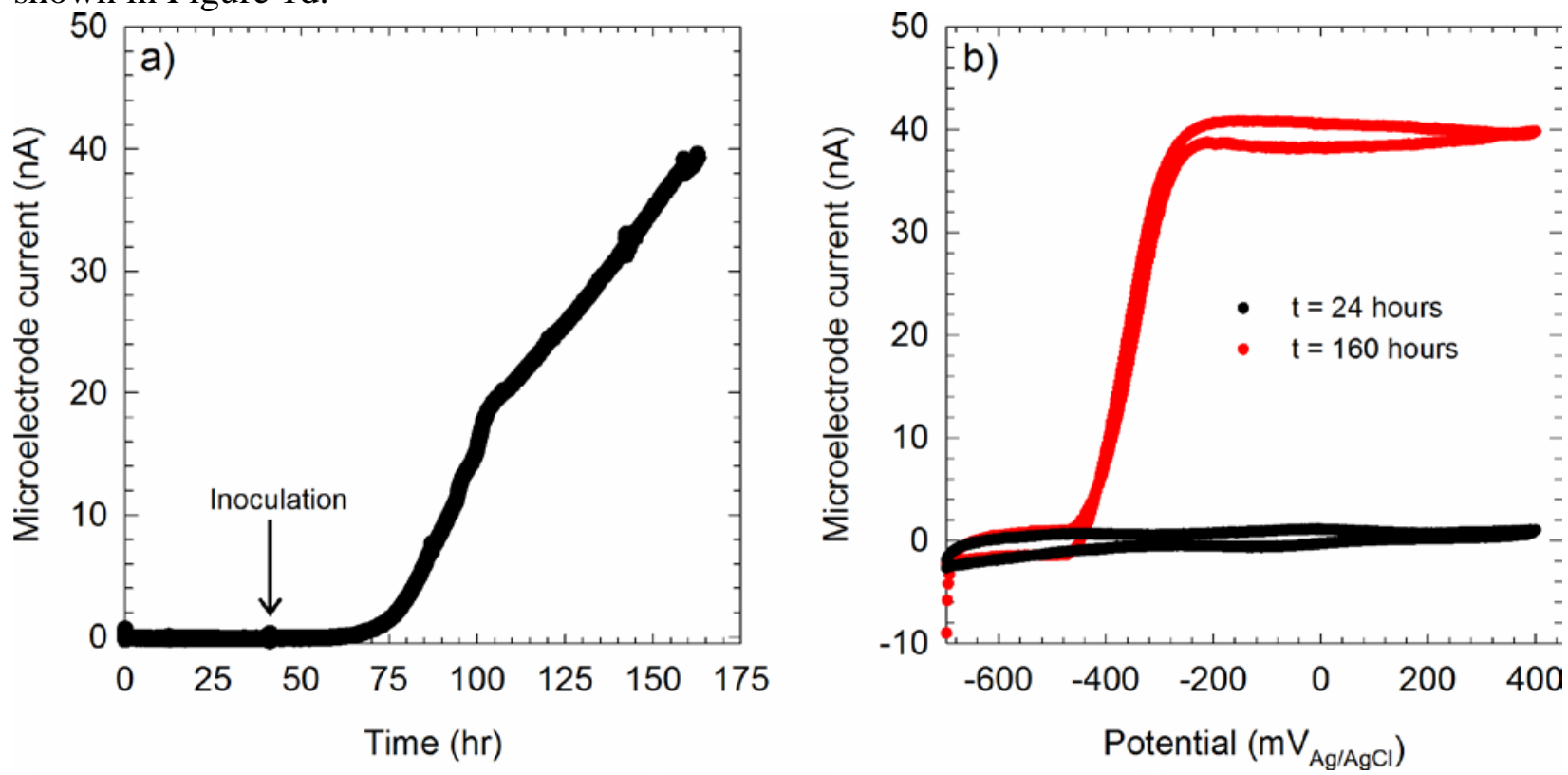

Figure 2. a) Current response of the G. sulfurreducens microelectrode-biofilm growth on the microelectrode tips. b) Cyclic voltammograms of G. sulfurreducens microelectrode-biofilm grown on a carbon microelectrode tip.

\subsection{Calibration of the acetate microbiosensor}

A calibration cell identical to the biofilm growth cell was used for the calibration. However, the medium was replaced with deoxygenated acetate-free medium. The microbiosensor was removed from the growth cell and $\sim 1 \mathrm{~mL}$ of deoxygenated acetate-free (non-turnover) medium was used to purge the outer case of medium containing acetate. After two rinses, the acetate microbiosensor was inserted into the calibration cell and was polarized at $+300 \mathrm{mV}_{\mathrm{Ag} / \mathrm{AgCl}}$. The potential of $+300 \mathrm{mV}_{\mathrm{Ag} / \mathrm{AgCl}}$, in the limiting current region (Figure $2 \mathrm{~b}$ ), was selected as the operation potential of the acetate microbiosensor. The microbiosensor current was allowed to reach a steady state before calibration. Aliquots of acetate solution from $1 \mathrm{M}$ sterilized deoxygenated stock was added to make 50, 100, 200, 400, 800, and $1600 \mu \mathrm{M}$ acetate concentrations.

\subsection{Testing for interference of electron donors and stirring effect}

Interference from lactate, formate, and pyruvate was tested by calibrating the microbiosensor in $1 \mathrm{mM}$ solutions of these compounds. Interference from hydrogen was tested by equilibrating the calibration solution with a gas mixture of $\mathrm{He} / \mathrm{H}_{2}(92 \% / 8 \%)$. Based on Henry's Law, the dissolved hydrogen concentration was calculated to be $64 \mu \mathrm{M}$ at $30{ }^{\circ} \mathrm{C}$ (Sander 2015). The interference responses observed for alternative electron donors were normalized with the acetate response to the same concentration of alternative electron donors and are reported as percentages of the response to acetate.

Since we used an open tip filled with liquid medium, it was necessary to determine whether this membraneless tip is immune to the stirring effect. To test this, a magnetic stirrer (IKA, catalog \#2669923) and a stir bar with a 2-cm diameter were used to agitate the calibration solution at 50,100, 150, and $200 \mathrm{rpm}$. The rpm values refer to the rotation rate of the stir bar at 
the base of the calibration chamber. Under these conditions, calibration curves were obtained and their slopes compared.

\subsection{Preparing electrode-respiring $G$. sulfurreducens biofilms to test the microbiosensor}

The utility of the acetate microbiosensor was tested by measuring acetate concentration profiles within macroscale G. sulfurreducens biofilms as described in Babauta et al.(Babauta et al. 2012). The biofilms were grown on a glassy carbon working electrode (SPI-Glas ${ }^{\mathrm{TM}}$ grade 11 ; $25 \mathrm{~mm} \times 25 \mathrm{~mm} \times 2 \mathrm{~mm}$ ) placed in a three-electrode bioreactor. A flat plate reactor which allowed us to perform microbiosensor measurements was used. The counter electrode was graphite (ground finish isomolded graphite plates, Glassmate grade GM-10, $25 \mathrm{~mm} \times 25 \mathrm{~mm}$ $\times 3 \mathrm{~mm}$, Poco Graphite, Inc., Decatur, TX), and the reference electrode was a $\mathrm{Ag} / \mathrm{AgCl}$ wire in $4 \mathrm{M} \mathrm{KCl}$ saturated with AgCl. All protocols were followed as in (Babauta et al. 2012) except that the reactor was operated in fed-batch with a $2-\mathrm{mL} / \mathrm{min}$ recirculation rate. The medium was replaced with fresh medium when the acetate was depleted in the medium. For acetate concentration depth profile measurements, the acetate concentration in the reactor was set to $1.5 \mathrm{mM}$ by considering the linear calibration range of the developed microbiosensor. The current generation of the $G$. sulfurreducens macro-biofilm during depth profile measurements at $+300 \mathrm{mV}_{\mathrm{Ag} / \mathrm{AgCl}}$ was $865 \pm 38 \mu \mathrm{A}$, and the open circuit potential (OCP) during OCP depth profile measurements was $-441 \pm 3 \mathrm{mV}_{\mathrm{Ag} / \mathrm{AgCl}}$.

\subsection{Measuring acetate concentration depth profiles in G. sulfurreducens biofilm}

First, a custom-built microprofiling system was set up around the biofilm reactor(Babauta et al. 2012). A three-axis micromanipulator with both a coarse (vertical) range of $10 \mathrm{~cm}$ and a motorized precision linear actuator (PI M-230.10S, Physik Instrumente, Auburn, MA, USA) controlled using custom-made LabVIEW software (National Instruments, Austin, TX, USA) was used to position the microbiosensor tip. The vertical range of the motorized actuator was $8 \mathrm{~mm}$ with a submicron step resolution. An adjacent stereomicroscope (Zeiss Stemi 2000) was used to locate the tip of the microbiosensor held by the micromanipulator. After the microprofiling system was set up, the microbiosensor was placed within the micromanipulator arm. Subsequently, the biofilm reactor was opened by removing the rubber stopper above the biofilm electrode. Using the coarse knobs on the micromanipulator, the microbiosensor tip was moved above the open port, lowered into the reactor volume, and positioned to approximately $100 \mu \mathrm{m}$ from the macro-biofilm surface. Custom-developed microprofiler software was then used to automate the measurement of acetate by depth from $100 \mu \mathrm{m}$ above the macro-biofilm surface to the electrode surface in $10-\mu \mathrm{m}$ increments. The software automatically recorded more than 20 data points for 100 secs for each location and reported the average and the standard deviation.

\section{Results and Discussion}

\subsection{Calibration of the microbiosensor}

The acetate microbiosensor is based on the conversion of acetate to electricity by a pregrown G. sulfurreducens microelectrode-biofilm. Initially the microelectrode-biofilm was kept in acetate-free solution within the outer case. Under this condition, the microelectrodebiofilm was dormant but capable of responding to acetate. Figure 3a shows the response of the microbiosensor to acetate additions starting from a baseline of zero acetate. The response time is defined as the time needed to reach 90\% of the final response (de Beer et al. 1997a; Suzuki et al. 
1999). The average response time of the acetate microbiosensor was $0.86 \pm 0.59$ min within the $0-1.6 \mathrm{mM}$ calibration range, and the response time was concentration-dependent above $0.4 \mathrm{mM}$ of acetate. While the response time was $0.54 \pm 0.11 \mathrm{~min}$ for the $0.05,0.1,0.2$ and $0.4 \mathrm{mM}$ acetate concentrations, it was $1 \mathrm{~min}$ and $2 \mathrm{~min}$ for the $0.8 \mathrm{mM}$ and $1.6 \mathrm{mM}$ acetate concentrations, respectively. This information provides the time that elapses before the microbiosensor is ready to measure another sample. Figure $3 \mathrm{~b}$ shows the correlation between the bulk acetate concentration and current generation. The inset extends the data points up to $6.4 \mathrm{mM}$ acetate to show that acetate saturation occurred at $3.2 \mathrm{mM}$. This is consistent with previous work (Tront et al. 2008), in which $2.3 \mathrm{mM}$ acetate provided the maximum current output and no increase in current was observed when the acetate concentration was above $2.3 \mathrm{mM}$. In addition, this type of nonlinear response is expected for a biosensor (Lewandowski and Beyenal 2014). The microbiosensor showed a linear response between $0.05 \mathrm{mM}$ and $1.6 \mathrm{mM}$ acetate concentrations with a $79 \pm 8 \mu \mathrm{M}$ limit of detection $(\mathrm{S} / \mathrm{N}=2)$ obtained from three independent calibrations.

We constructed multiple microbiosensors and calibrated them. We note that each microbiosensor had a unique calibration curve based on the mass of pre-grown biofilm on the microelectrode tip. We found that the calibration range was consistent but the variation in the slopes was $1.98 \pm 0.95 \mathrm{nA} / \mathrm{mM}(\mathrm{n}=3)$. The background current varied between 0 and $15 \mathrm{nA}$. The background current could be reduced to zero nA if we waited long enough. However, the background current did not cause any impact on the calibration.

We should note that the current density of the microelectrode-biofilm was $56.6 \mathrm{~A} / \mathrm{m}^{2}$ at the end of 160 hours of growth. In replicated experiments, the current density varied between 42.4 and $70.7 \mathrm{~A} / \mathrm{m}^{2}$. This current density was extremely high compared to that of $G$. sulfurreducens biofilms growing on larger electrodes (Babauta et al. 2012; Nevin et al. 2008). For example, in our system, for the biofilms growing on the larger electrode (where we measured acetate concentration depth profiles) the maximum current density was $3.88 \mathrm{~A} / \mathrm{m}^{2}$. In addition, Nevin et al. reported a current density of $3.1 \mathrm{~A} / \mathrm{m}^{2}$ on graphite anodes (Nevin et al. 2008). The reasons for these high current densities for smaller electrodes are not known and are still in debate (Beyenal and Babauta 2015; Call and Logan 2011). In our case, the high current density generated by microelectrode biofilms and their small size allow them to be more sensitive and have a quicker response time. The superiority of microbiosensors over their larger-size equivalents is already well known in the literature (Bard and Faulkner 2000; Lewandowski and Beyenal 2014). 

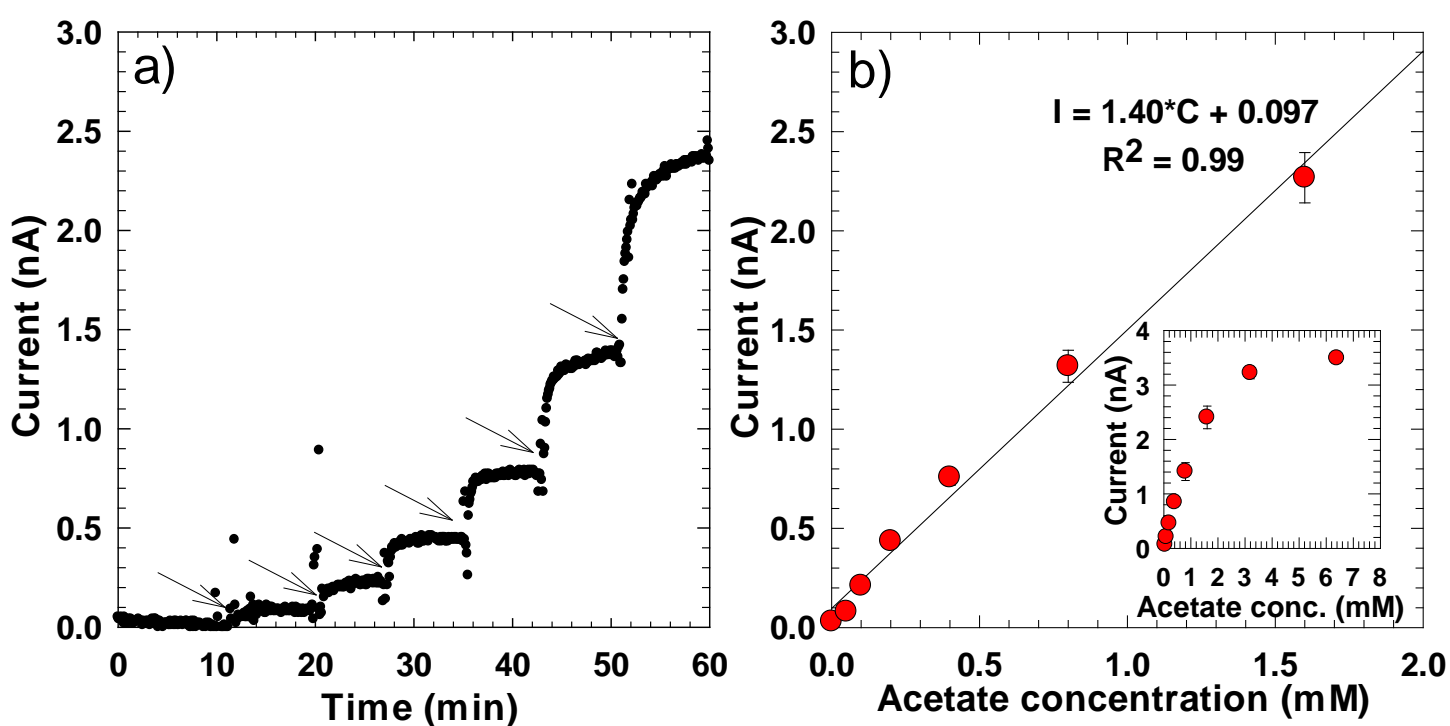

Figure 3. a) Acetate microbiosensor responses to acetate additions marked with arrows. Each addition corresponds to a concentration shown in b). b) Calibration between 0 and $1.6 \mathrm{mM}$ acetate concentrations. The inset figure shows the variation of current with acetate concentration for 0-6.4 mM acetate concentrations.

\subsection{Interfering effects of alternative electron donors}

G. sulfurreducens biofilms are expected to use alternative electron donors. Lactate, formate, pyruvate, and hydrogen could illicit current responses that would interfere with acetate measurement (Speers and Reguera 2012). Therefore, we tested the current responses of the acetate microbiosensor to these alternative electron donors at their equivalent concentrations of acetate. Figure 4 shows that the presence of lactate, formate, pyruvate, or hydrogen induced an increase in current of $11 \% \pm 1.7 \%, 39 \% \pm 6.2 \%, 15 \% \pm 3.0 \%$, or $19 \% \pm 3.7 \%$, respectively. The microelectrode-biofilm is most sensitive towards formate, indicating that variation in formate concentration should be accounted for. However, when the measurements were performed without these alternative electron donors, the acetate microbiosensor provided reliable results.

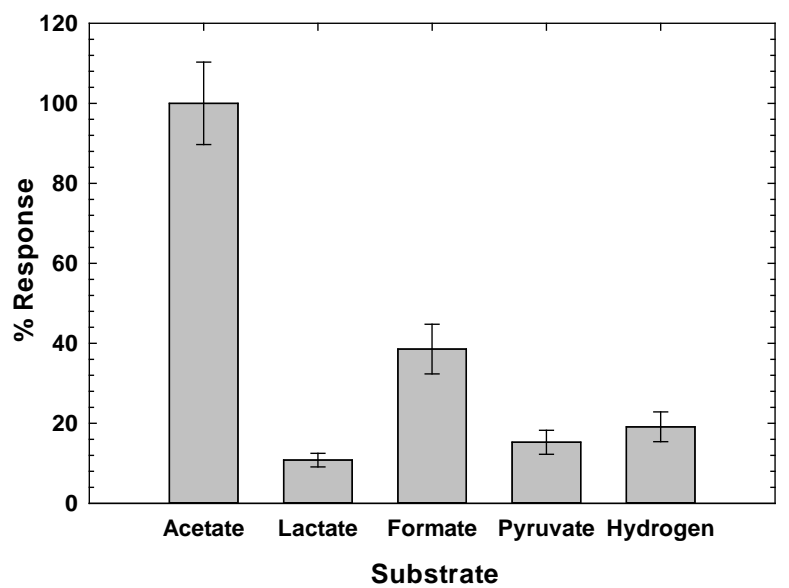

Figure 4. Response of the acetate microbiosensor to a range of substrates measured as a 


\subsection{Interfering effect of convection on the microbiosensor response}

The acetate microbiosensor employs a 200- $\mu$ m-long cylindrical open diffusion barrier that separates the microelectrode-biofilm from the external environment. Because it is open to the external environment, however, we had to ensure that convection did not alter the microbiosensor response. Figure 5 shows the effect of stirring on the acetate microbiosensor calibration from $0 \mathrm{mM}$ to $1.6 \mathrm{mM}$ bulk acetate concentration. The rpm value refers to the rotation rate of the stir bar at the base of the calibration chamber, and the Reynolds numbers (Re) calculated for 50, 100, 150 and 200 rpm stirring rates are 333, 667, 1000, and 1333, respectively. It has been reported that $\mathrm{Re}=100$ is the transition from laminar flow to turbulent flow and $\mathrm{Re}=$ 1000 is highly turbulent flow (Nauman 2008). The tests at a wide range of Re confirmed that we tested microbiosensors in laminar and turbulent zones. From $50 \mathrm{rpm}$ to $200 \mathrm{rpm}$, there was no detectable effect on the calibration slope. This proves that the diffusion barrier adequately separated the internal environment of the acetate microbiosensor from the external environment and verified that the diffusion barrier acted as a membrane.

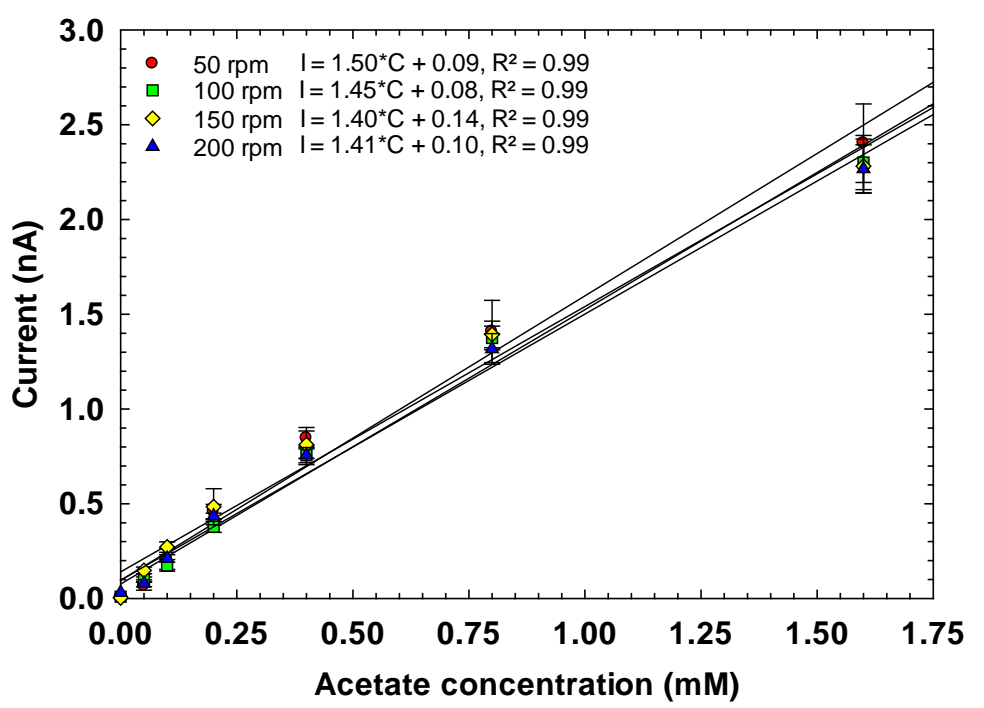

344

Figure 5. Effect of stirring on the acetate microbiosensor calibration slope at stirring rates of 50, 100, 150, and $200 \mathrm{rpm}$. There is no detectable effect on the calibration slopes.

\subsection{Acetate concentration depth profile measurements within a G. sulfurreducens biofilm}

Figure 6 shows the acetate concentration depth profiles measured within $G$. sulfurreducens biofilm when 1) no current was passed at the open circuit potential and 2) current was passed at a polarization potential of $+300 \mathrm{mV}_{\mathrm{Ag} / \mathrm{AgCl}}$. At the open circuit potential, the acetate concentration remained at bulk values throughout the macro-biofilm regardless of location. When current was allowed to pass, a decrease in acetate was observed from the bulk value to below the detection limit at the base of the biofilm. A similar result for acetate utilization in substantially thicker G. sulfurreducens biofilms was observed using EC-NMR (Renslow et al. 2013). However, the minimum detection limit of the acetate microbiosensor described here was substantially improved, from $\mathrm{mM}$ to $\mu \mathrm{M}$. The depth profile demonstrates that the biofilm consisted of two layers: a top layer oxidizing acetate and a bottom without acetate. The bottom of the biofilm served as a scaffold for the acetate-oxidizing layer to transfer electrons to the electrode. This finding agrees with the previous publication demonstrating a two-layered G. sulfurreducens biofilm with a metabolically active top and an acetate-limited bottom (Renslow et al. 2013). 

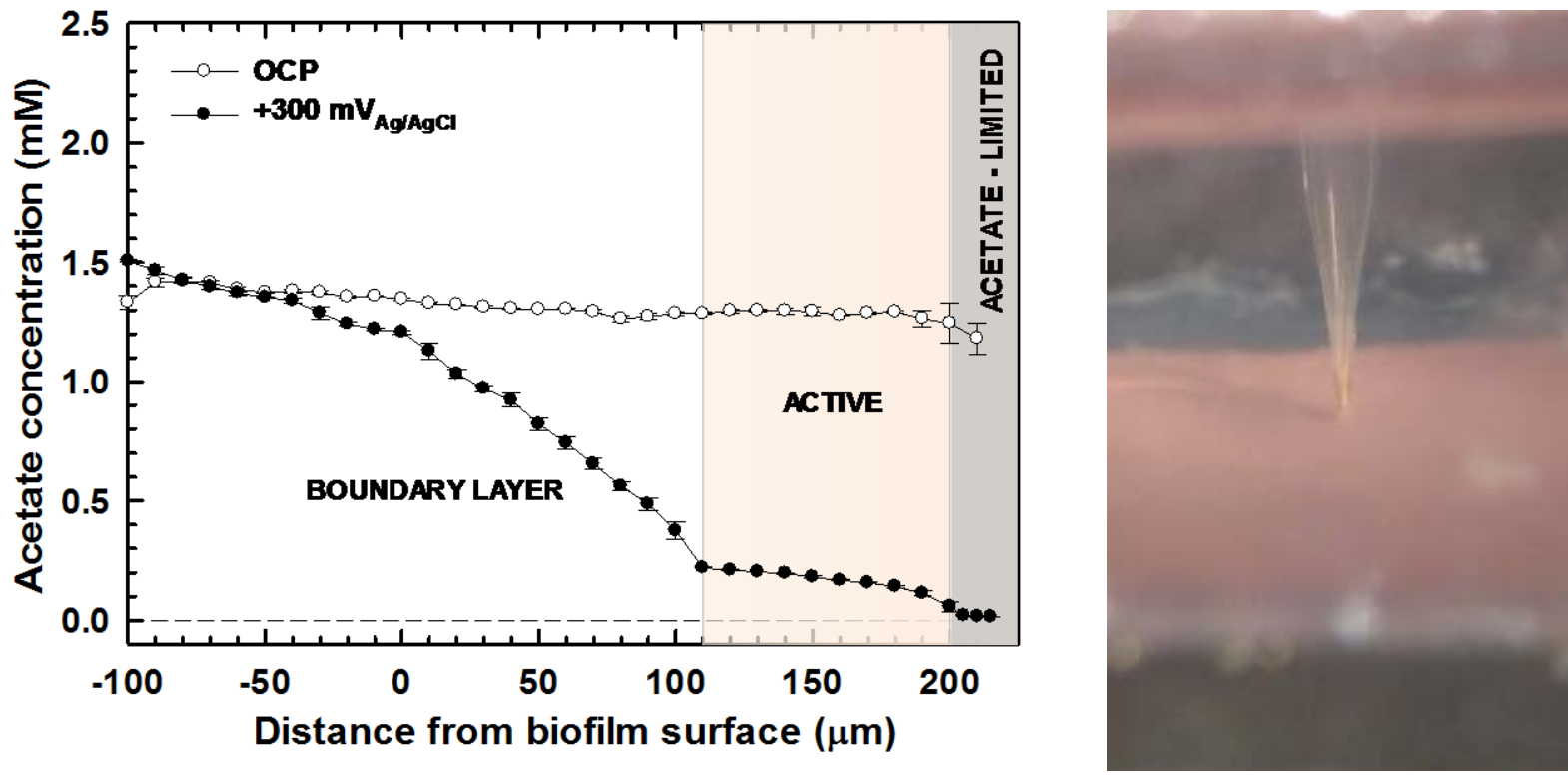

Figure 6.Acetate concentration depth profiles in G. sulfurreducens biofilms in OCP mode and at $+300 \mathrm{mV}_{\mathrm{Ag} / \mathrm{AgCl}}$ polarization. The photo on the right shows the biofilm and the acetate microbiosensor entering the biofilm. In some cases the error bar is smaller than the average and is not visible.

\subsection{Potential applications of the acetate microbiosensor}

Although our primary goal in developing the acetate microbiosensor was to understand the acetate limitations in electrode-respiring biofilms, the use of the developed microbiosensor can be extended to various applications in which acetate is utilized as a substrate. The developed microbiosensor can be used to measure acetate concentrations either in bulk solutions or inside biofilms in situ. For example, acetate is consumed or produced during anaerobic conversion in wastewater treatment and in anaerobic digestion processes (Estevez-Canales et al. 2015; Henze 2008). In addition, there is a need to measure acetate concentrations in the polyphosphateaccumulating biofilms that use acetate as the main electron donor in biological phosphorus removal processes (Meyer et al. 2002; Sudiana et al. 1999). Overall, the developed microbiosensor can be used to measure acetate concentration and its variation by depth in many anaerobic biofilms in $\mu \mathrm{M}$ resolution. It is also advantageous to use a microbiosensor rather than a macroscale sensor to monitor acetate concentrations in bulk solutions because the small size of the electrode tip provides faster response times, lower detection limits and higher resolutions than a large electrode (Beyenal and Babauta 2014). The developed microbiosensor can be modified for electron acceptors such as nitrate and fumarate since G. sulfurreducens biofilms can reduce nitrate and fumarate when a solid electrode is used as an electron donor (Choi and Sang 2016; Gregory et al. 2004; Pous et al. 2016). To achieve this, the operation of the microbiosensor should be switched to a cathodic mode by setting an appropriate potential. Therefore, the developed membraneless acetate microbiosensor can provide a platform for developing microbiosensors that detect organic compounds other than acetate. 


\section{Conclusions}

391 In this work, we developed and tested an acetate microbiosensor based on G. sulfurreducens. 392 The microbiosensor consisted of a 30- $\mu$ m-thick carbon microelectrode as the working electrode 393 with $G$. sulfurreducens biofilm on the tip and a $\mathrm{Ag} / \mathrm{AgCl}$ reference electrode, all enclosed in a

394 glass outer case. The microbiosensor was operated at $+300 \mathrm{mV}$ Ag/AgCl. The microbiosensor was 395 calibrated between 0 and $6.4 \mathrm{mM}$ acetate concentrations and showed a linear response between 0 396 and $1.6 \mathrm{mM}$ acetate concentrations with a $79 \pm 8 \mu \mathrm{M}$ limit of detection (S/N=2). The 397 microbiosensor was immune to the stirring effect. Using the acetate microbiosensor, we 398 successfully measured acetate concentrations inside G. sulfurreducens biofilm grown on a glassy 399 carbon electrode. The measurements revealed that the acetate concentration was at the bulk 400 concentration throughout the biofilm at the open circuit potential, when the biofilm was not 401 respiring, but that the acetate concentration decreased below the detection limit within the $402200-\mu \mathrm{m}$ thickness of the biofilm when the electrode was polarized at $+300 \mathrm{mV}$ Ag/AgCl. These 403 measurements demonstrate that the biofilm consisted of two layers: a top oxidizing acetate and a 404 bottom without acetate. The bottom of the biofilm served as a scaffold for the acetate-oxidizing 405 layer to transfer electrons to the electrode.

\section{Acknowledgements}

408 This research is supported by the U.S. Office of Naval Research (ONR), grant \#N00014-09-1409 0090. The authors thank Phuc T. Ha for her help in providing some of the G. sulfurreducens 410 inoculums. 


\section{References}

412 Babauta, J.T., Beyenal, H., 2014a. J. Electrochem. Soc. 161, H3070-H3075. Babauta, J.T., Beyenal, H., 2014b. Biotechnol. Bioeng. 111, 285-294. Babauta, J.T., Nguyen, H.D., Harrington, T.D., Renslow, R., Beyenal, H., 2012. Biotechnol. Bioeng. 109, 2651-2662. Bard, A.J., Faulkner, L.R., 2000. Electrochemical Methods: Fundamentals and Applications. Wiley. Beyenal, H., Babauta, J., 2014. Microsensors and Microscale Gradients in Biofilms, in: Muffler, K., Ulber, R. (Eds.), Productive Biofilms. Springer International Publishing, pp. 235-256. Beyenal, H., Babauta, J.T., 2015. Biofilms in Bioelectrochemical Systems: From Laboratory Practice to Data Interpretation. Wiley.

Beyenal, H., Davis, C.C., Lewandowski, Z., 2004. Sensor. Actuat. B-Chem. 97, 202-210. Bond, D.R., Lovley, D.R., 2003. Appl. Environ. Microbiol. 69, 1548-1555.

Call, D.F., Logan, B.E., 2011. Biosens. Bioelectron. 26, 4526-4531.

Choi, O., Sang, B.-I., 2016. Biotechnol. Biofuels 9, 1-14.

Cronenberg, C.C.H., van den Heuvel, J.C., 1991. Biosens. Bioelectron. 6, 255-262.

Damgaard, L.R., Revsbech, N.P., 1997. Anal. Chem. 69, 2262-2267.

de Beer, D., Glud, A., Epping, E., Kûhl, M., 1997a. Limnol. Oceanogr. 42, 1590-1600.

De Beer, D., Schramm, A., Santegoeds, C.M., Kuhl, M., 1997b. Appl. Environ. Microbiol. 63, 973-977.

Du, Z., Li, H., Gu, T., 2007. Biotechnol. Adv. 25, 464-482.

Fricke, K., Harnisch, F., Schroder, U., 2008. Energy Environ. Sci. 1, 144-147.

Gregory, K.B., Bond, D.R., Lovley, D.R., 2004. Environ. Microbiol. 6, 596-604.

Hamelers, H.M., Ter Heijne, A., Sleutels, T.J.A., Jeremiasse, A., Strik, D.B.T.B., Buisman, C.N., 2010. Appl. Microbiol. Biotechnol. 85, 1673-1685.

He, Z., Angenent, L.T., 2006. Electroanal. 18, 2009-2015.

Henze, M., 2008. Biological Wastewater Treatment: Principles, Modelling and Design. IWA Pub.

Jeroschewski, P., Steuckart, C., Kühl, M., 1996. Anal. Chem. 68, 4351-4357.

Larsen, L.H., Revsbech, N.P., Binnerup, S.J., 1996. Appl. Environ. Microbiol. 62, 1248-1251.

Lee, J.-H., Seo, Y., Lim, T.-S., Bishop, P.L., Papautsky, I., 2007. Environ. Sci. Technol. 41, 7857-7863.

Lewandowski, Z., Beyenal, H., 2003. Use of microsensors to study biofilms, in: Lens, P., O'Flaherty, V., Moran, A., Stoodley, P. and Mahony, T. (Eds.), Biofilms in Medicine, Industry and Environmental Biotechnology: Characteristics, Analysis and Control. IWA Publishing, London, pp. 375-412.

Lewandowski, Z., Beyenal, H., 2014. Fundamentals of Biofilm Research, Second Edition. Taylor \& Francis.

Lewandowski, Z., Lee, W.C., Characklis, W.G., Little, B., 1989. Corrosion 45, 92-98.

Liu, X., Roe, F., Jesaitis, A., Lewandowski, Z., 1998. Biotechnol. Bioeng. 59, 156-162.

Logan, B.E., 2009. Nat. Rev. Microbiol. 7, 375-381.

Logan, B.E., Hamelers, B., Rozendal, R., Schröder, U., Keller, J., Freguia, S., Aelterman, P., Verstraete, W., Rabaey, K., 2006. Environ. Sci. Technol. 40, 5181-5192.

Logan, B.E., Rabaey, K., 2012. Science 337, 686-690.

Lovley, D.R., 2006. Curr. Opin. Biotechnol. 17, 327-332. 
McLamore, E.S., Shi, J., Jaroch, D., Claussen, J.C., Uchida, A., Jiang, Y., Zhang, W., Donkin, 458 S.S., Banks, M.K., Buhman, K.K., Teegarden, D., Rickus, J.L., Porterfield, D.M., 2011. 459 Biosens. Bioelectron. 26, 2237-2245.

460 Meyer, R.L., Larsen, L.H., Revsbech, N.P., 2002. Appl. Environ. Microbiol. 68, 1204-1210.

461 Nauman, E.B., 2008. Chemical Reactor Design, Optimization, and Scaleup. Wiley.

462 Nevin, K.P., Richter, H., Covalla, S.F., Johnson, J.P., Woodard, T.L., Orloff, A.L., Jia, H., 463 Zhang, M., Lovley, D.R., 2008. Environ. Microbiol. 10, 2505-2514.

464 Nguyen, H.D., Renslow, R., Babauta, J., Ahmed, B., Beyenal, H., 2012. Sensor. Actuat. B465 Chem. 161, 929-937.

466 Peteu, S.F., Emerson, D., Mark Worden, R., 1996. Biosens. Bioelectron. 11, 1059-1071.

467 Pous, N., Carmona-Martínez, A.A., Vilajeliu-Pons, A., Fiset, E., Bañeras, L., Trably, E., 468 Balaguer, M.D., Colprim, J., Bernet, N., Puig, S., 2016. Biosens. Bioelectron. 75, 352-358.

469 Reguera, G., McCarthy, K.D., Mehta, T., Nicoll, J.S., Tuominen, M.T., Lovley, D.R., 2005. $470 \quad$ Nature 435, 1098-1101.

471 Renslow, R.S., Babauta, J.T., Dohnalkova, A.C., Boyanov, M.I., Kemner, K.M., Majors, P.D., 472 Fredrickson, J.K., Beyenal, H., 2013. Energy Environ. Sci. 6, 1827-1836.

473 Sander, R., 2015. Atmos. Chem. Phys. 15, 4399-4981.

474 Speers, A.M., Reguera, G., 2012. Appl. Environ. Microbiol. 78, 437-444.

475 Sudiana, I.M., Mino, T., Satoh, H., Nakamura, K., Matsuo, T., 1999. Water Sci. Technol. 39, 476 29-35.

477 Suzuki, H., Arakawa, H., Sasaki, S., Karube, I., 1999. Anal. Chem. 71, 1737-1743.

478 Tront, J.M., Fortner, J.D., Plötze, M., Hughes, J.B., Puzrin, A.M., 2008. Biosens. Bioelectron. 479 24, 586-590.

480 VanHoudt, P., Lewandowski, Z., Little, B., 1992. Biotechnol. Bioeng. 40, 601-608. 